\title{
Medical Management of Orbital Myiasis using $0.1 \%$ w/v Topical Ivermectin Preparation in a Calf
}

\author{
Khan Sharun $^{1 *}$ and K.M. Manjusha ${ }^{2}$ \\ ${ }^{1}$ Division of Surgery, ICAR-Indian Veterinary Research Institute, \\ Izatnagar, Bareilly, Uttar Pradesh, India \\ ${ }^{2}$ College of Veterinary and Animal Sciences, Mannuthy, Thrissur, Kerala Veterinary and \\ Animal Sciences University, India \\ *Corresponding author
}

\begin{abstract}
A B S T R A C T

\begin{tabular}{|l|}
\hline Keyw ord s \\
Calf, Maggot \\
wound, Myiasis, \\
Ivermectin \\
\hline Article Info \\
\hline $\begin{array}{l}\text { Accepted: } \\
15 \text { April } 2019 \\
\text { Available Online: } \\
\text { 10 May } 2019\end{array}$ \\
\hline
\end{tabular}

Myiasis occurs when open wounds are infested with larvae of Diptera flies. A three day old female calf was presented with a history of ocular injury which was complicated by secondary maggot infestation in the medial canthus of the right eye. The ocular injury occurred as a complication of manual correction of dystocia using eye hooks. On general clinical examination, the physiological parameters were found to be within the normal range. Ophthalmic examination of the eye revealed that the animal was blind in the right eye. Physical examination of the eyes revealed the presence of numerous live maggots in the medial canthus of right eye. The corneal surface and conjunctiva were edematous. Following the removal of live maggots, $0.1 \%$ ivermectin preparation was used topically for three days for removing the remaining live maggots. The calf was also treated with Flurbiprofen, Tobramycin and Hypertonic Sodium Chloride ophthalmic drops for one month. The calf regained the eyesight and recovered uneventfully following the treatment.
\end{abstract}

\section{Introduction}

Myiasis occurs when open wounds are infested with larvae of Diptera flies. There will be a severe decrease in feeding due to the severe irritation and annoyance produced secondary to the maggot wound (Rahman et al., 2009). As a consequence the production output of the animal will also be affected. Cattle is the most common host for myiasis but it can also occur in dogs, humans, pigs, horses and sheep (Bermúdez et al., 2007). The flies that are responsible for causing maggot wounds are attracted to open wounds or natural body openings with foul smelling discharge. Even the smallest of the wounds are the potential targets of such flies (Hall and Wall, 1995). After hatching, the larva invades the broken skin and burrow into the dermal layers. The larvae start feeding on the tissue that causes serious tissue damage thereby resulting in the loss of condition and injury to the hide (Humphrey et al., 1980). Orbital myiasis if left untreated can cause severe damage to the globe due to burying nature of maggots. It can also damage the neighboring 
structures like the paranasal sinuses or the intracranial cavity (Jain et al., 2007).

The primary aim in the treatment of maggot wound is to remove the burrowed maggots and thereby facilitating wound healing. Maggots can be removed by killing it with either turpentine oil or dehydrating the maggots using hypertonic saline (Puthran et $a l ., 2012)$. But there are certain limitations in choosing the maggoticidal agents for sensitive tissues like the eye. Hence, non-irritant and safe agents should be used for the treatment of orbital myiasis. Topical treatment with $1 \%$ ivermectin in a propylene glycol solution was found to be a safe and effective treatment in the management of maggot wound (Victoria et al., 1999).

The present case report describes the treatment of orbital myiasis using $0.1 \% \mathrm{w} / \mathrm{v}$ topical Ivermectin preparation in a three day old calf which occurred secondary to eye hook injury due to the manual correction of dystocia.

\section{History and diagnosis}

A three day old calf was presented with a history of the swollen and inflamed right eye following parturition due to damage produced by the eye hook used to retrieve the calf during manual correction of dystocia. On general clinical examination, all of the physiological parameters were found to be within the normal range.

Physical examination revealed that the medial canthus of right eye was injured deeply and extensively. Further examination of the right eye revealed the presence of numerous live maggots in the medial canthus of right eyes. Ophthalmic examination of the eye revealed that the animal was blind in the right eye. The corneal surface and conjunctiva were edematous. The right eye was also showing excessive lacrimation along with chemosis.

\section{Treatment}

Ocular injuries always present a challenge in the treatment aspect as far as vision is concerned. Firstly, the live maggots were removed using forceps. $0.1 \%$ ivermectin drops were prepared by dissolving $10 \mathrm{mg}$ tablet of ivermectin in $10 \mathrm{ml}$ distilled water to obtain a preparation containing $1 \mathrm{mg}$ ivermectin per milliliter of distilled water $(0.1 \% \mathrm{w} / \mathrm{v})$. The prepared topical preparation was instilled into the eye and the remaining maggots were removed. Topical $0.1 \%$ ivermectin drops were continued for three days. Advised to instill Flurbiprofen $(0.03 \%$ $\mathrm{w} / \mathrm{v})$, Tobramycin $(0.3 \% \mathrm{w} / \mathrm{v})$ and Sodium Chloride $(5 \% \mathrm{w} / \mathrm{v})$ ophthalmic drops at a dose of three drops four times daily with an interval of 30 minutes between each drug instillation.

\section{Results and Discussion}

There was a progressive improvement in the condition of the animal following the therapy. The maggot wound started to heal soon after the treatment was initiated. The clarity of the cornea improved and became completely clear on day 30. Ophthalmological examination on day 30 revealed that the animal regained its vision completely. Topical $0.1 \% \mathrm{w} / \mathrm{v}$ Ivermectin preparation was found to be effective in the treatment of orbital myiasis in the three day old calf.

Myiasis occurs when dead or living vertebrate tissues are infested by dipterous larvae that feed on them. This results in host tissue destruction and subsequent economic losses to livestock rearing worldwide (Otranto, 2001). Ivermectin, the broad-spectrum antiparasitic drug is considered as the safest and noninvasive method of treating maggot wounds that are buried deep in the orbital tissues (Osorio et al., 2006) (Fig. 1 and 2). 
Fig.1 Three day old calf brought with the history of orbital myiasis secondary to eye hook injury due to the manual correction of dystocia (Left). Removing the live maggots from the wound in the medial canthus of the right eye (Right)
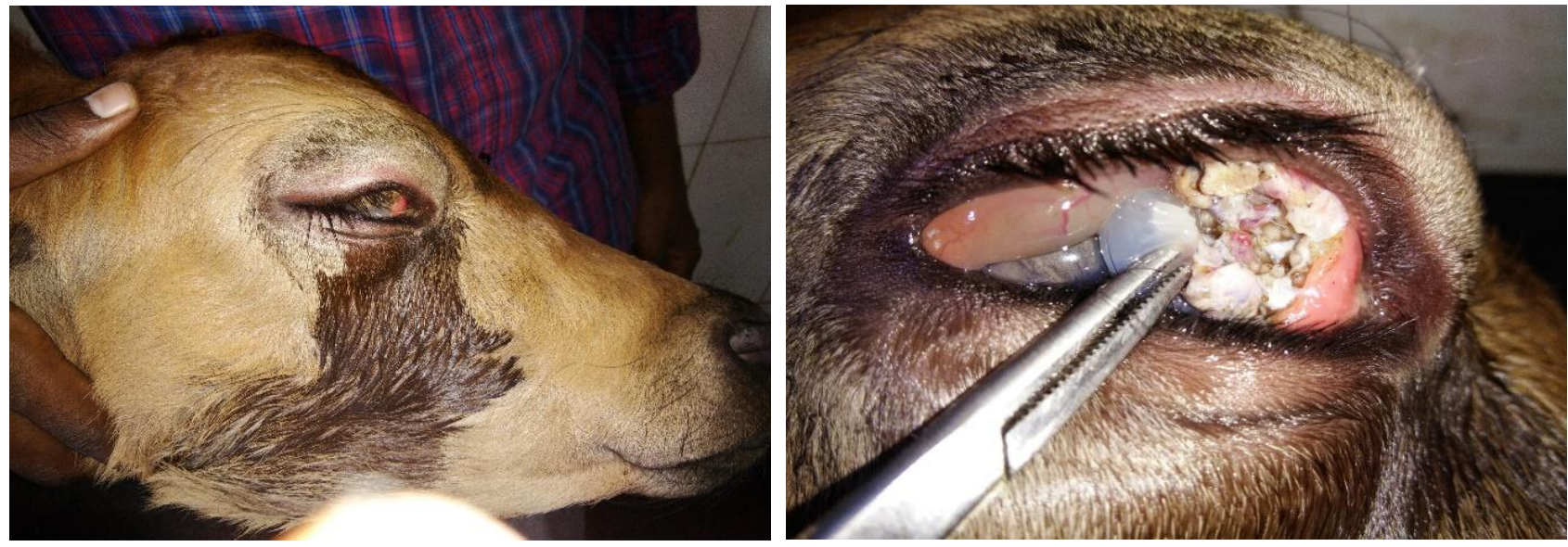

Fig.2 Progressive healing of the orbital maggot wound - Day 1, Day 3, Day 15, and Day 30
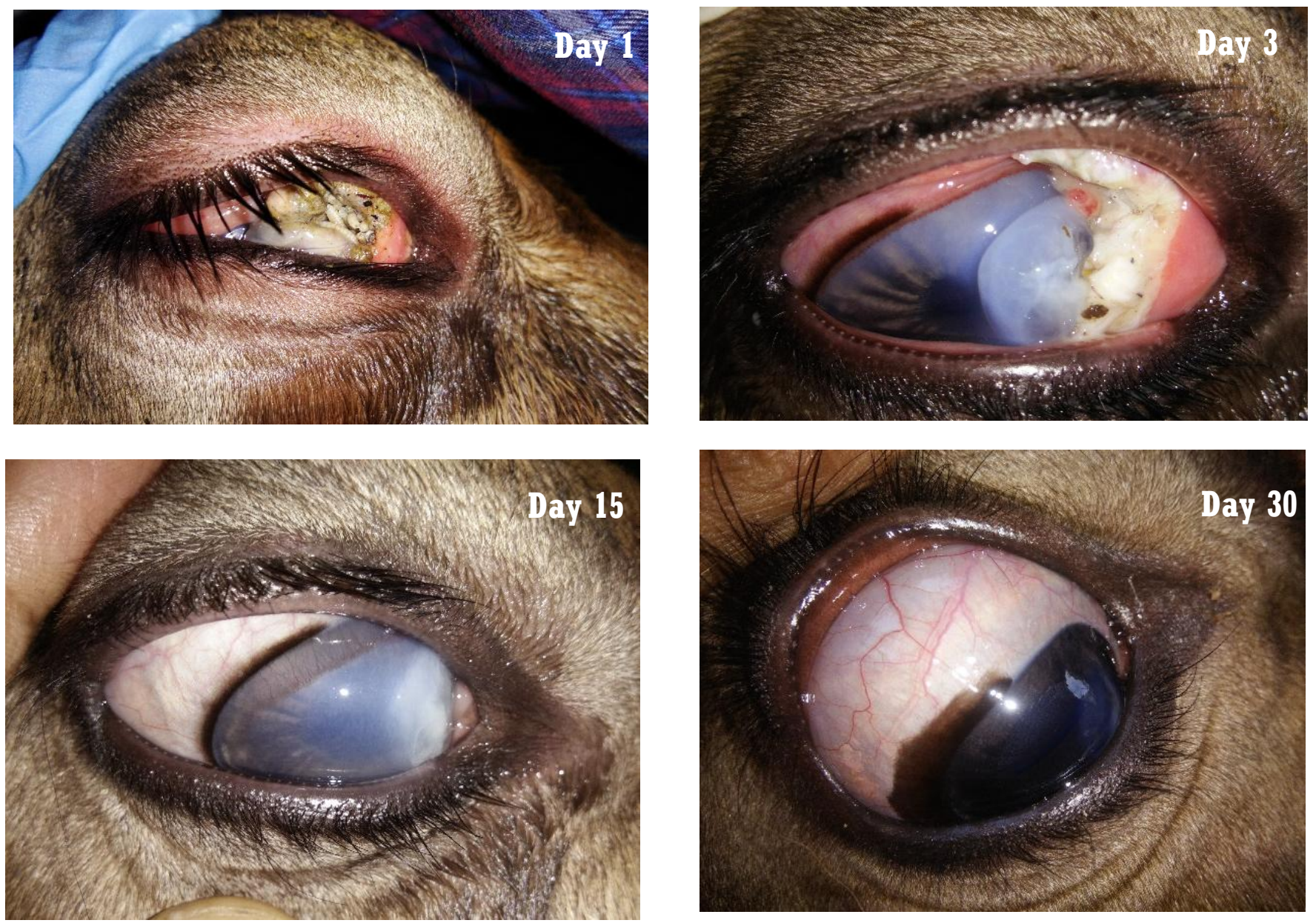
Several topical drug preparations other than ivermectin are also used for the treatment of myiasis. Topical application of $1 \%$ fipronil was found to be effective in managing myiasis in cattle. Even though fipronil does not have repellant action, it is an effective larvicide with $100 \%$ curative efficacy (Lima et al., 2004).

Chemotherapeutic agents like organophosphates and macrocyclic lactones are been successfully used for the control and treatment of myiasis-causing larvae, but there are several constraints while using such drugs like the possibility of animal toxicity, parasitic resistance, meat - milk residues and environmental pollution (Otranto, 2001). Topical use of ivermectin can be considered as a superior alternative to oral and parenteral use of ivermectin in reducing the above mentioned lacunas. Hence $0.1 \%$ w/v topical ivermectin was used in the present case for the treatment of orbital myiasis.

Treatment of maggot wound is easy, but it can be challenging in certain sensitive tissues like eyes. Improper treatment may result in blindness secondary to the extensive damage to the globe and hence prompt treatment is mandatory in the treatment of orbital myiasis. In the present case, the animal was blind during the presentation due to the initial insult to the cornea that resulted in edema and corneal opacity. Topical $0.1 \% \mathrm{w} / \mathrm{v}$ Ivermectin preparation was found to be effective in killing the deeply burrowed maggots in the orbital maggot wound. Other supportive therapies also helped in the complete recovery of the damaged eye. The calf regained the eyesight and recovered uneventfully following the treatment.

\section{References}

Bermúdez, S.E., Espinosa, J.D., Cielo, A.B., Clavel, F., Subía, J., Barrios, S. and
Medianero, E., 2007. Incidence of myiasis in Panama during the eradication of Cochliomyia hominivorax (Coquerel 1858, Diptera: Calliphoridae) (2002-2005). Memórias do Instituto Oswaldo Cruz, 102(6), pp.675-679.

Hall, M. and Wall, R., 1995. Myiasis of humans and domestic animals. In Advances in parasitology (Vol. 35, pp. 257-334). Academic Press.

Humphrey, J.D., Spradbery, J.P. and Tozer, R.S., 1980. Chrysomya bezziana: pathology of old world screw-worm fly infestations in cattle. Experimental parasitology, 49(3), pp.381-397.

Jain, A., Desai, R.U. and Ehrlich, J., 2007. Fulminant orbital myiasis in the developed world. British Journal of Ophthalmology, 91(11), pp.15651566.

Lima, W.S., Malacco, M.A.F., Bordin, E.L. and Oliveira, E.L., 2004. Evaluation of the prophylactic effect and curative efficacy of fipronil $1 \%$ pour on (Topline®) on post-castration scrotal myiasis caused by Cochliomyia hominivorax in cattle. Veterinary parasitology, 125(3-4), pp.373-377.

Osorio, J., Moncada, L., Molano, A., Valderrama, S., Gualtero, S. and Franco-Paredes, C., 2006. Role of ivermectin in the treatment of severe orbital myiasis due to Cochliomyia hominivorax. Clinical infectious diseases, 43(6), pp. e57-e59.

Otranto, D., 2001. The immunology of myiasis: parasite survival and host defense strategies. TRENDS in Parasitology, 17(4), pp.176-182.

Puthran, N., Hegde, V., Anupama, B. and Andrew, S., 2012. Ivermectin treatment for massive orbital myiasis in an empty socket with concomitant scalp pediculosis. Indian Journal of Ophthalmology, 60(3), p.225. 
Rahman, M.A., Hossain, M.A. and Alam, M.R. 2009. Clinical evaluation of different treatment regimes for management of myiasis in cattle. Bangladesh Journal of Veterinary Medicine, 7(2), pp. 348352.
Victoria, J., Trujillo, R. and Barreto, M., 1999. Myiasis: a successful treatment with topical ivermectin. International journal of dermatology,38(2), pp. 142-144.

\section{How to cite this article:}

Khan Sharun and Manjusha, K.M. 2019. Medical Management of Orbital Myiasis using 0.1\% w/v Topical Ivermectin Preparation in a Calf. Int.J.Curr.Microbiol.App.Sci. 8(05): 1796-1800. doi: https://doi.org/10.20546/ijcmas.2019.805.208 